\title{
Influence of Gender and Undergraduate Course on the Knowledge about HPV and HPV Vaccine, and Vaccination Rate among Students of a Public University
}

\section{A influência do gênero e do curso de graduação no conhecimento sobre o HPV e sua vacina, e taxa de vacinação em estudantes de uma universidade pública}

\author{
Marília Biselli-Monteiro ${ }^{10}$ Amanda Canato Ferracini ${ }^{1}{ }^{\circledR}$ Luis Otávio Sarian ${ }^{1}{ }^{\circledR 0}$ \\ Sophie Françoise Mauricette Derchain ${ }^{10}$ \\ ${ }^{1}$ Department of Obstetrics and Gynecology, Medical School, \\ Universidade Estadual de Campinas, Campinas, SP, Brazil \\ Rev Bras Ginecol Obstet 2020;42(2):96-105. \\ Address for correspondence Marília Biselli-Monteiro, MD, \\ Universidade Estadual de Campinas, Cidade Universitária Zeferino \\ Vaz - Barão Geraldo, Campinas, SP, 13083-970, Brazil \\ (e-mail: ma_biselli@hotmail.com).
}

\section{Abstract}

Keywords

- human papillomavirus

- vaccine

- students

- knowledge

- vaccination rate

Objective To evaluate the knowledge related to human papillomavirus (HPV) infection and the rate of HPV vaccination among undergraduate freshmen and senior students of medicine, pharmacy, speech therapy, nursing and physical education in a Brazilian university.

Methods A questionnaire concerning sociodemographic aspects, sexual background, and knowledge about HPV and its vaccine was filled out by 492 students. Three months later, a second questionnaire, concerning the new rate of vaccination, was applied to 233 students.

Results Among the 290 women who answered the first questionnaire, $47 \%$ of the freshmen and $13 \%$ of the seniors stated they were not sexually active, as well as $11 \%$ of the 202 freshman and senior male students. Although the knowledge about HPV was higher among women, they reported a lower use of condoms. More than $83 \%$ of the women and $66 \%$ of the men knew that HPV can cause cervical cancer, but less than $30 \%$ of the students knew that HPV can cause vulvar, anal, penile and oropharyngeal cancer. Less than half of the students knew that HPV causes genital, anal and oropharyngeal warts. Comparing the students, the seniors had more knowledge of the fact that HPV is sexually transmitted, and that HPV infection can be asymptomatic. The rate of vaccination was of $26 \%$ for women, and of $8 \%$ for men, and it increased to $52 \%$ and $27 \%$ respectively among the 233 students evaluated in the second questionnaire. Conclusion As almost half of freshman women declared being sexually inactive, the investment in public health information programs and easier access to the HPV vaccine seem to be a useful strategy for undergraduate students.
\end{abstract}

received

July 5, 2019

accepted

November 22, 2019
DOI https://doi.org/

10.1055/s-0040-1701466. ISSN 0100-7203.
Copyright (e 2020 by Thieme Revinter

Publicações Ltda, Rio de Janeiro, Brazil
License terms

(c) (1) 


\section{Resumo}

\author{
Palavras-chave \\ - vírus do papiloma \\ humano \\ - vacina \\ - estudantes \\ - conhecimento \\ - taxa de vacinação
}

Objetivo Avaliar o conhecimento sobre a infecção pelo vírus do papiloma humano (human papillomavirus, HPV, em inglês) e a taxa de vacinação entre estudantes calouros e veteranos do quarto ano dos cursos de medicina, farmácia, fonoaudiologia, enfermagem e educação física de uma universidade brasileira.

Métodos Um primeiro questionário sobre aspectos sociodemográficos, antecedentes sexuais e conhecimento sobre o HPV e sua vacina foi aplicado a 492 estudantes. Três meses depois, foi aplicado um novo questionário, a 233 estudantes, que avaliava a nova taxa de vacinação entre eles.

Resultados Entre as 290 mulheres que responderam ao questionário, 47\% das calouras e $13 \%$ das veteranas negaram início de atividade sexual. Entre os 202 calouros e veteranos do sexo masculino avaliados, essa taxa foi de $11 \%$. Apesar de o conhecimento sobre o HPV ter sido maior entre as mulheres, elas declararam menor uso de preservativo. Mais de $83 \%$ das mulheres e $66 \%$ dos homens sabiam que o HPV causa câncer de colo de útero, mas menos de $30 \%$ de todos os alunos sabiam que o HPV pode causar câncer de vulva, ânus, pênis e orofaringe, e menos de 50\% sabiam que o HPV pode causar verrugas genitais, anais e orofaríngeas. Comparando calouros e veteranos, houve um aumento no conhecimento de que o HPV é sexualmente transmitido, e de que sua infecção pode ser assintomática, entre os veteranos em comparação com os calouros. Pela taxa de vacinação analisada no segundo questionário, identificou-se que, antes do início da pesquisa, $26 \%$ das mulheres e $8 \%$ dos homens haviam sido vacinados, e, no momento da aplicação do segundo questionário, essas taxas subiram para $52 \%$ e $27 \%$, respectivamente, entre os 233 alunos avaliados.

Conclusão Quase metade das calouras relataram não ser sexualmente ativas, e a maioria delas ainda não era vacinada contra o HPV. O ingresso no Ensino Superior parece um momento oportuno para a realização de campanhas governamentais de conscientização e vacinação contra o HPV.

\section{Introduction}

Current academic knowledge pertaining to human papillomavirus (HPV) infection and its relationship with human pathology is vast and well established. Decades of cumulative investigation led to a firm amalgam of information concerning the biological basis for the different effects of HPV infection on the cervix, vulva, penis, anus and oropharynx. ${ }^{1}$ In essence, HPV is the major causal factor for genital warts and multiple cancers such as cervical, vulvar, vaginal, oropharyngeal, penile and anal cancer. ${ }^{2}$ Cervical cancer is the third most prevalent neoplasm and the fourth leading cause of death by cancer among women. ${ }^{3}$ The prevention of HPV infection can be accomplished through prophylactic vaccines, which, administered prior to the contact with the virus, provide almost $100 \%$ of efficacy. The vaccines are prophylactic, and have their greatest benefit in boys and girls who have not yet started their sexual activity. Sexually active adolescents and young adults are also vaccinated to catch up. ${ }^{2}$ The first vaccine against HPV has been approved by the US Food and Drug Administration (FDA) in 2006; however, the global vaccination rate for girls aged 10 to 20 years by 2015 was of $6.1 \%{ }^{4}$

In spite of the unequivocal progress obtained in the diagnosis, treatment and prevention of HPV infection, sever- al studies suggest that the awareness and knowledge about the infection, its causes and risk factors among the population is surprisingly limited. Alarmingly, it is known that higher knowledge about HPV and its consequences is related to a higher propensity to take the vaccine, ${ }^{5}$ and ignorance on the part of the general population about the implications of HPV infection to general health is highly associated with the failure of prevention initiatives. McCusker et $\mathrm{al}^{6}$ applied a questionnaire concerning knowledge about HPV to freshman medicine students at a university in Scotland. The students participated later in a public health information (PHI) campaign that described the role of HPV in the development of cervical cancer. After the PHI, they observed a significant increase in the rate of HPV vaccination among girls: in 2008, before the campaign, no girl had taken all three doses of the vaccine; however, one year after the intervention, more than $58 \%$ were vaccinated. They also reported that after this campaign, $94 \%$ of the vaccinated girls understood that they should remain in the screening program. ${ }^{6}$

It is therefore clear that awareness about HPV infection and its consequences among the general population is surprisingly low considering the consolidated academic knowledge about it, its clinical implications, and the ample amount of diagnostic and therapeutic tools currently available. Even more alarming, 
a few pioneering studies suggest that in the developed and developing world, young adults studying in healthcare-related undergraduate programs may display unacceptable low levels of knowledge about HPV infections as well. Our hypothesis is that freshman students go to college between the ages of 18 and 25 years, and, therefore, are at a high risk for HPV infection, but only a small proportion of those students are vaccinated against HPV. Our objective was to perform a comprehensive longitudinal evaluation of the knowledge related to HPV and HPV vaccination, among freshman and senior undergraduate students of medicine, pharmacy, speech therapy, nursing and physical education in an extremely competitive Brazilian university. We also evaluated the proportion of students already vaccinated before the questionnaire, and the proportion of those who took the vaccine within three months of the application of the questionnaire.

\section{Methods}

The present was an observational cohort study. After approval by the Ethics in Research Committee of Universidade Estadual de Campinas (Unicamp, in Portuguese) (under CAAE 64275917.4.0000.5404), a questionnaire was applied in August 2017 to freshman and senior undergraduate students aged $\geq 18$ years of the courses of medicine, nursing, speech therapy, pharmacy and physical education of Unicamp. All subjects signed the free and informed consent form. The questionnaire was composed of 79 multiple-choice, true or false, and short answers; it included sociodemographic aspects, sexual background, knowledge on HPV and the vaccine, and the rates of vaccination and of intention to indicate the vaccine to girls and boys in their professional future. After the students filled out the questionnaire, a sheet with the correct answers was offered to them. A second questionnaire with 5 questions was applied in November 2017 to 233 students, with the objective of analyzing the vaccination rate of the medicine and pharmacy undergraduates, and to evaluate if those who had participated in the first part of the survey were more likely to get vaccinated. The transcription of the questionnaire data was performed using the REDCap (Vanderbilt University, Nashville, TN, US) web application. The data was then exported and analyzed using the R Environment for Statistical Computing (R Foundation for Statistical Computing, Vienna, Austria). ${ }^{7}$ The Chisquared test for trends and the $t$-test were used to evaluate differences in knowledge across the groups of students, as well as the changes in the vaccination rate before and after the application of the questionnaires. Due to the small number of students and the similarity in the sociodemographic characteristics, the data obtained from the speech therapy and nursing students were grouped.

\section{Results}

\section{Sociodemografic Factors}

Among the 492 students included in the present study, there were 290 women and 202 men. In total, there were 196 medicine students, 63 pharmacy students, 39 speech therapy students, 44 nursing students, and 147 physical education students. There were 279 (56.7\%) freshmen and 213 (43.3\%) seniors. The proportion of female students was significantly higher in the nursing (97.7\%) and speech therapy (94.9\%) courses compared with pharmacy $(79.7 \%)$, medicine $(57.4 \%)$ and physical education $(31.3 \%)(p<0.001)$. A significantly larger proportion of medical students reported living alone, in boarding homes or with friends, compared with those of other courses, who most often reported living with their parents. The rate of students who declared themselves as followers of a religion was higher among the nursing and speech therapy students when compared with those of other courses $(p<0.05)$. Most students reported having graduated from high school in a public or technical school, excluding the pharmacy students. The proportion of students who had at least one parent that was a college graduate was significantly higher among the pharmacy (74.2\%) and medicine (77.6\%) students compared with the physical education (61\%) and nursing/speech therapy (50\%) students $(p<0.01)$ ( - Table 1 ).

\section{Sexual Background}

-Table 2 shows that although most women self-declared as heterosexuals, there was a significantly higher proportion of bisexuals among freshman students (13.2\%) when compared to the seniors $(4 \%)(p<0.05)$. There was no difference in the proportion of heterosexuals, homosexuals and bisexuals among female and male students $(p>0.05)$. Only 63\% of freshmen women reported having started sexual activity, and, among the seniors, $13.4 \%$ of women reported they were not yet sexually active. Among the freshman and senior male students, more than $89 \%$ reported they were sexually active. The proportion of sexually active men (89\%) among the freshman males was significantly higher when compared with that of women $(p<0.001)$. The reported age of initiation of sexual activity was significantly lower among men when compared with women $(p<0.001)$. Women reported a higher rate of stable relationships than men $(p<0.05)$. We observed that women reported more visits to the gynecologist than men to the urologist ( $p<0.001$ ), and having or not health insurance was not associated with a higher rate of consultations. Condom use was reported by more than $90 \%$ of the freshman and senior male students and by only $61.8 \%$ of freshman female students and $57.3 \%$ of senior female students.

\section{Knowledge about HPV and the Vaccine}

- Table 3 shows the proportion of correct responses to specific questions evaluating HPV-related knowledge. Of the 14 proposed questions, the proportion of senior female students answering correctly was significantly higher for 9 questions compared with their freshman counterparts, regardless of the undergraduate course. For men, in 12 out of the 14 questions, the proportion of senior students answering correctly was higher than that of their freshman counterparts. Comparing male and female students, regardless of class and course, in $6 / 14$ questions the proportion of women answering correctly a question was higher than that of men. In general, - Table 3 shows a clear progression of HPV-related knowledge throughout the years and a higher level of HPV-related education among women compared with men. For instance, the rate of 
Table 1 Sociodemographic characteristics of the study sample

\begin{tabular}{|c|c|c|c|c|c|c|c|}
\hline $\begin{array}{l}\text { Sociodemographic } \\
\text { characteristics }\end{array}$ & $\begin{array}{l}\text { Physical } \\
\text { education } \\
\mathrm{n}(\%) \\
\end{array}$ & $\begin{array}{l}\text { Speech } \\
\text { therapy } \\
\mathrm{n}(\%)\end{array}$ & $\begin{array}{l}\text { Nursing } \\
\mathrm{n}(\%)\end{array}$ & $\begin{array}{l}\text { Nursing and } \\
\text { speech therapy } \\
\mathrm{n}(\%)\end{array}$ & $\begin{array}{l}\text { Pharmacy } \\
\mathrm{n}(\%)\end{array}$ & $\begin{array}{l}\text { Medicine } \\
\mathrm{n}(\%)\end{array}$ & $p$-value \\
\hline \multicolumn{8}{|l|}{ Gender } \\
\hline Male & $101(68.7)$ & $2(5.1)$ & $1(2.3)$ & $3(3.6)$ & $12(19)$ & $83(42.3)$ & $p<0.001$ \\
\hline Female & $46(31.3)$ & $37(94.9)$ & $43(97.7)$ & $80(96.4)$ & $51(81)$ & $113(57.7)$ & \\
\hline \multicolumn{8}{|l|}{ Class } \\
\hline Freshman & $90(61.2)$ & 23(59) & 29(65.9) & $52(62.7)$ & $32(50.8)$ & 104(53.1) & $p>0.05$ \\
\hline Senior & $57(38.8)$ & $16(41)$ & $15(34.1)$ & $31(37.3)$ & $31(49.2)$ & $92(46.9)$ & \\
\hline \multicolumn{8}{|l|}{ Residence situation } \\
\hline $\begin{array}{l}\text { Living with parents } \\
\text { or guardians }\end{array}$ & $90(62.9)$ & $20(52.6)$ & $21(48.8)$ & $41(50.1)$ & $29(49.2)$ & $43(22.3)$ & $p<0.001$ \\
\hline $\begin{array}{l}\text { Living alone or in a } \\
\text { fraternity/sorority }\end{array}$ & $53(37.1)$ & $18(47.4)$ & $22(51.2)$ & $40(49.9)$ & $30(50.8)$ & $150(77.7)$ & \\
\hline \multicolumn{8}{|l|}{ Follower of a religion } \\
\hline Yes & $90(61.6)$ & $32(82.1)$ & $34(79.1)$ & $66(80.5)$ & $36(58.1)$ & $122(62.2)$ & $p<0.05$ \\
\hline No & $56(3.4)$ & $7(17.9)$ & $9(20.9)$ & $16(19.5)$ & $26(41.9)$ & $74(37.8)$ & \\
\hline \multicolumn{8}{|l|}{ High school institution } \\
\hline Public school & $44(29.9)$ & $13(34.2)$ & $15(34.1)$ & $28(34.2)$ & 11(17.5) & $64(32.7)$ & $p>0.05$ \\
\hline Technical school & $38(25.9)$ & $10(26.3)$ & $10(22.7)$ & $20(24.4)$ & $15(23.8)$ & $44(22.4)$ & $p>0.05$ \\
\hline Private school & $65(44.2)$ & 15(39.5) & 19(43.2) & $34(41.4)$ & $37(58.7)$ & $88(44.9)$ & $p<0.05$ \\
\hline \multicolumn{8}{|c|}{ Schooling of the parents } \\
\hline Higher education & $89(61)$ & $18(46.2)$ & $23(53.5)$ & $41(50)$ & $46(74.2)$ & 152(77.6) & $p<0.001$ \\
\hline High school & $45(30.8)$ & $17(43.6)$ & $13(30.2)$ & $30(36.6)$ & $10(16.1)$ & $38(30.8)$ & $p<0.05$ \\
\hline $\begin{array}{l}\text { Did not graduate } \\
\text { from high school }\end{array}$ & $12(8.2)$ & $4(10.3)$ & $7(16.3)$ & $11(13.4)$ & $6(9.7)$ & $6(3.1)$ & $p<0.001$ \\
\hline
\end{tabular}

Notes: $p$ : comparison of all courses. ${ }^{*}$ The analyses were compromised due to less than 5 answers. Because of the similarity between the data from nursing and pharmacy students, and the small number of students in those groups, the courses were grouped for the sake of analysis. ${ }^{* *}$ The percentages were calculated based on the number of students that answered the question.

knowledge that HPV is a sexually transmitted infection (STI) was high among freshman and senior female students (91.4\% and $95.3 \%$ respectively) and among freshman and senior male students (82.3\% and $94.2 \%$ respectively), being significantly lower among freshman male students $(p<0.05)$. The rate of knowledge that HPV can cause cervical cancer was of $82.2 \%$ and $85.8 \%$ among female freshmen and seniors respectively, and of $63.5 \%$ and $69.8 \%$ male freshmen and seniors respectively $(p<0.001)$. However, concerning the knowledge of other cancers related to HPV infection, such as vulvar, vaginal, anal, penile and oropharyngeal cancers, the accuracy rate was lower than $40 \%$ for both genders, with a significant increase in correct answers among senior students $(p<0.001)$. The percentage of students who knew that HPV can cause different types of warts was lower than the percentage of students who knew HPV could cause cervical cancer. However, this knowledge was higher among the senior compared with the freshman female students $(62.7 \%$ and $37.4 \%$ respectively), and among the senior compared with the freshman male students (58.1\% and $22.6 \%$ respectively).

We observed a trend in general HPV-related knowledge among female and male students. - Fig. 1A shows the compar- ison between the women of the different courses: we observed that physical education students know less about HPV infection and its consequences than those of speech therapy and nursing, who know less than pharmacy students, who, in turn, know less than medical students ( $p$-trend $<0.001$ ). The accuracy rate in the questions that stated that HPV is an STI that can affect both genders and can cause cervical cancer was higher than $60 \%$ among all of the women, and obeyed the proposed standard ( $p$-trend $<0.001$ ). On the other hand, knowledge that HPV has a higher prevalence among young adults aged 15 to 25 years did not show any difference between the courses ( $p$-trend $>0.05$ ). Knowledge that HPV infection is most often asymptomatic, that the infection may become latent and cause genital, anal and oropharyngeal warts showed a large difference among courses ( $p$-trend $<0.001$ ). Only $32.6 \%$ of physical education students knew that HPV can be asymptomatic, compared with $52.5 \%$ of speech therapy/nursing students, $74.5 \%$ of pharmacy students, and $77 \%$ of medicine students. As for the knowledge that warts can be caused by HPV, $30.4 \%$ of physical education students, $40.5 \%$ of speech therapy/nursing students, $47.1 \%$ of pharmacy students, and $61.9 \%$ of medicine students knew about this correlation. Regarding the other cancers related to HPV 
Table 2 Sexual background comparing gender and class

\begin{tabular}{|c|c|c|c|c|c|c|c|}
\hline Answer & $\begin{array}{l}\text { Freshman } \\
\text { women } \\
\mathrm{n}(\%)\end{array}$ & $\begin{array}{l}\text { Senior } \\
\text { women } \\
n(\%)\end{array}$ & $p 1$ & $\begin{array}{l}\text { Freshman } \\
\text { men } \\
\mathrm{n}(\%)\end{array}$ & $\begin{array}{l}\text { Senior } \\
\text { men } \\
n(\%)\end{array}$ & $p 2$ & $p 3$ \\
\hline \multicolumn{8}{|c|}{ Average age (standard deviation) } \\
\hline & $19.71(1.88)$ & $22.87(2.50)$ & & $20.79(3.59)$ & $23.44(2.53)$ & & \\
\hline \multicolumn{8}{|l|}{ Sexual orientation } \\
\hline Heterossexual & $133(83.6)$ & $117(93.6)$ & $p<0.05$ & $98(87.5)$ & $70(86.4)$ & $p>0.05$ & $p>0.05$ \\
\hline Homossexual & $5(3.1)$ & $3(2.4)$ & $p>0.05^{*}$ & $7(6.2)$ & $8(9.9)$ & $p>0.05$ & $p>0.05$ \\
\hline Bissexual & $21(13.2)$ & $5(4)$ & $p<0.05$ & $7(6.2)$ & $3(3.7)$ & $p>0.05^{*}$ & $p>0.05^{*}$ \\
\hline \multicolumn{8}{|c|}{ If the student had ever gone to a gynecologist or urologist } \\
\hline Yes & $143(87.7)$ & $120(94.5)$ & $p<0.05$ & $30(26.5)$ & $23(26.7)$ & $p>0.05$ & $p<0.001$ \\
\hline No/don't remember & $20(12.3)$ & $7(5.5)$ & $p<0.05$ & $83(73.5)$ & $63(73.3)$ & $p>0.05$ & $p<0.001$ \\
\hline \multicolumn{8}{|l|}{ Sexually active } \\
\hline Yes & 102(63) & $110(86.6)$ & $p<0.001$ & $102(89.5)$ & $76(89.4)$ & $p>0.05$ & $p<0.001$ \\
\hline No & $60(37)$ & $17(13.4)$ & $p<0.001$ & $12(10.5)$ & $9(10.6)$ & $p>0.05$ & $p<0.001$ \\
\hline \multicolumn{8}{|l|}{ Age at first intercourse } \\
\hline & $17.12(1.61)$ & $18(2.23)$ & & $16.67(1.52)$ & $17.16(1.98)$ & & $p<0.001$ \\
\hline \multicolumn{8}{|c|}{ If engaged in a serious relationship } \\
\hline Yes & $69(42.9)$ & $75(59.5)$ & $p<0.05$ & $41(35.7)$ & $41(48.2)$ & $p>0.05$ & $p<0.05$ \\
\hline No & $92(57.1)$ & $51(40.5)$ & $p<0.05$ & $74(64.3)$ & $44(51.8)$ & $p>0.05$ & $p<0.05$ \\
\hline \multicolumn{8}{|l|}{ Uses condom } \\
\hline Yes & $63(61.8)$ & $63(57.3)$ & $p>0.05$ & $100(98)$ & 71(93.4) & $p>0.05$ & $p<0.001$ \\
\hline No & $39(38.2)$ & $47(42.7)$ & $p>0.05$ & $2(2)$ & $5(6.6)$ & $p>0.05$ & $p<0.001^{*}$ \\
\hline \multicolumn{8}{|l|}{ If has life insurance } \\
\hline Yes & $114(71.2)$ & $100(78.7)$ & $p>0.05$ & $72(63.2)$ & $68(79.1)$ & $p<0.05$ & $p>0.05$ \\
\hline No & $46(28.7)$ & $27(21.3)$ & $p>0.05$ & $42(36.8)$ & 18(20.9) & $p<0.05$ & $p>0.05$ \\
\hline
\end{tabular}

Abbreviations: p1, comparing freshman and senior women; p2, comparing freshman and senior men; $p 3$, comparing women and men. Notes: ${ }^{*}$ Analyses compromised due to less than 5 answers had been filled out in the questionnaire. ${ }^{* *}$ The percentages were calculated based on the number of people that answered the question.

infection, the percentage of right answers among all of the women was below $40 \%$. In the case of anal and anorectal cancer, the rate was of $8.7 \%$ of physical education students, $19.2 \%$ of speech therapy/ nursing students, $18 \%$ of pharmacy students, and $34.5 \%$ of medicine students ( $p$-trend $<0.001$ ). In the case of oropharyngeal cancer, $6.5 \%$ of physical education students, $12.8 \%$ of speech therapy/nursing students, $8 \%$ of pharmacy students, and $33.6 \%$ of medicine students recognized HPV as a cause ( $p$-trend $<0.001$ ). Regarding the relationship between infection and the development of penile cancer, the percentage of correct answers among women was of $10.9 \%$ of physical education students, $16.7 \%$ of speech therapy/nursing students, $16 \%$ of pharmacy students, and $26.5 \%$ of medicine students ( $p$-trend $<0.05)$.

-Fig. 1B shows the proportion of correct answers by male participants for the questions measuring HPV-related knowledge. Physical education students have less knowledge about HPV infection and its consequences than pharmacy students, who, in turn, score worse than medicine students ( $p$-trend $<0.001$ ). Due to the small number of male students in the nursing and speech therapy courses, the inclusion of them in the analyses was compromised. The percentage of correct answers regarding the sexually transmitted character of HPV infection was higher than $75 \%$ for all courses, with $81.6 \%$ for physical education, $91.7 \%$ for pharmacy and $94 \%$ for medicine ( $p$-trend $<0.05$ ). As for the knowledge that both genders can be affected and that the infection has a higher incidence among those aged between 15 and 25 years, the percentage of correct answers was of $81.8 \%$ and $59 \%$ respectively among physical education students, $75 \%$ and $75 \%$ respectively among pharmacy students, and $94 \%$ and $69.9 \%$ respectively among medicine students. Concerning the asymptomatic nature of the majority of HPV infections, physical education students obtained a rate of $30 \%$ of correct answers, while the rate for the pharmacy students was of $58.3 \%$, and of $72.3 \%$ for the medicine students ( $p$-trend $<0.001$ ). Few male students knew that HPV causes genital, anal and oropharyngeal warts (17\% of physical education, $33.3 \%$ of pharmacy and $65.1 \%$ of medicine students; $p$-trend $<0.001$ ). For the question about the causal role of HPV in cervical cancer, the rate of correct answers ranged from $46 \%$ for the physical education students, and $66.7 \%$ for the pharmacy students, to $92.8 \%$ for the medical students 
Table 3 Knowledge about HPV comparing gender and class

\begin{tabular}{|c|c|c|c|c|c|c|c|}
\hline Questions & $\begin{array}{l}\text { Freshman } \\
\text { women } \\
\mathrm{n}(\%)\end{array}$ & $\begin{array}{l}\text { Senior } \\
\text { women } \\
n(\%)\end{array}$ & $p 1$ & $\begin{array}{l}\text { Freshman } \\
\text { men } \\
\mathrm{n}(\%)\end{array}$ & $\begin{array}{l}\text { Senior } \\
\text { men } \\
\mathrm{n}(\%)\end{array}$ & $p 2$ & p3 \\
\hline HPV is a sexually transmitted infection & 149(91.4) & $121(95.3)$ & $p>0.05$ & $93(82.3)$ & $81(94.2)$ & $p<0.05$ & $p<0.05$ \\
\hline HPV is common & $134(82.7)$ & $109(85.8)$ & $p>0.05$ & $68(59.6)$ & $71(82.6)$ & $p<0.001$ & $p<0.001$ \\
\hline Both genders can be affected by HPV & $144(88.3)$ & 115(90.6) & $p>0.05$ & $95(83.3)$ & $77(89.5)$ & $p>0.05$ & $p>0.05$ \\
\hline $\begin{array}{l}\text { The incidence of HPV is higher } \\
\text { between } 15 \text { and } 25 \text { years old }\end{array}$ & $115(70.6)$ & $105(82.7)$ & $p<0.05$ & $69(60)$ & $63(73.3)$ & $p<0.05$ & $p<0.05$ \\
\hline Most infections are asymptomatic & $82(50.3)$ & $100(78.7)$ & $p<0.001$ & $40(34.8)$ & $58(67.4)$ & $p<0.001$ & $p<0.05$ \\
\hline The infection can become latent & $101(62)$ & $94(74)$ & $p<0.05$ & $63(54.3)$ & $63(73.3)$ & $p<0.05$ & $p>0.05$ \\
\hline The infection can persist & $121(74.2)$ & $90(70.9)$ & $p>0.05$ & $73(62.9)$ & $66(76.7)$ & $p<0.05$ & $p>0.05$ \\
\hline $\begin{array}{l}\text { HPV can cause genital, } \\
\text { anal and oropharyngeal warts }\end{array}$ & $61(37.4)$ & $79(62.7)$ & $p<0.001$ & $26(22.6)$ & $50(58.1)$ & $p<0.001$ & $p<0.05$ \\
\hline HPV can cause cervical cancer & $134(82.2)$ & $109(85.8 \%)$ & $p>0.05$ & $73(63.5)$ & $60(69.8)$ & $p>0.05$ & $p<0.001$ \\
\hline HPV can cause vaginal cancer & $27(16.8)$ & $46(36.5)$ & $p<0.001$ & $11(9.6)$ & $28(32.6)$ & $p<0.001$ & $p>0.05$ \\
\hline $\begin{array}{l}\text { HPV can cause anal } \\
\text { and anorectal cancer }\end{array}$ & $22(13.7)$ & $45(35.7)$ & $p<0.001$ & $9(7.9)$ & $34(39.5)$ & $p<0.001$ & $\mathrm{p}>0.05$ \\
\hline HPV can cause penile cancer & 17(10.6) & $39(31)$ & $p<0.001$ & $14(12.3)$ & $32(37.2)$ & $p<0.001$ & $p>0.05$ \\
\hline HPV can cause oropharyngeal cancer & $15(9.3)$ & $40(31.7)$ & $p<0.001$ & $8(7)$ & $25(29.1)$ & $p<0.001$ & $p>0.05$ \\
\hline $\begin{array}{l}\text { The types of HPV that cause warts are } \\
\text { different from those that cause cancer }\end{array}$ & $18(11)$ & $54(42.5)$ & $p<0.001$ & $9(7.8)$ & $32(37.2)$ & $p<0.001$ & $p>0.05$ \\
\hline
\end{tabular}

Abbreviations: $p 1$, comparing freshman and senior women; $p 2$, comparing freshman and senior men; $p 3$, comparing women and men. Note: The percentages were calculated based on the number of people that answered the question.

( $p$-trend $<0.001$ ). As of other cancers related to HPV, the rate of correct answers was low, with penile cancer being reported as a possible consequence of HPV infection by $10.1 \%$ of physical education students, $41.7 \%$ of pharmacy students, and $37.3 \%$ of those studying medicine.

\section{Attitude toward the Vaccine among Non-immunized Students and Intention to Indicate the Vaccine}

- Table 4 shows that the rate of women (26\%) who had taken the HPV vaccine prior to the application of the first questionnaire was significantly higher than that of men (8\%) $(p<0.001)$, regardless of the class and course. As for age at vaccination, there was a higher rate of freshman women who took the vaccine until age 17 , and only 10 women took the vaccine until age 14 (data not shown). There was no difference in the proportion of girls vaccinated against HPV among the courses (data not shown). Non-vaccinated freshman women reported a greater interest in taking the vaccine (74.3\%) than the seniors $(61.4 \%)(p<0.05)$. The intention to take the vaccine did not differ between women according to the course (data not shown). The intention to take the vaccine was significantly higher among unvaccinated women than among unvaccinated men $(p<0.05)$. Among men who did not take the vaccine, there was a higher proportion of pharmacy students that intended to take the vaccine compared with those of other courses (data not shown). Most men and women who answered the questionnaire would recommend the vaccine for both genders, and this proportion was higher among senior women (75.6\%) than among freshman women $(60.7 \%)(p<0,05)$.

\section{Vaccination against HPV before and after Filling out the First Questionnaire}

Among the 233 students who answered the second questionnaire, which was applied 3 months after the first one, 39 women (28 medicine and 11 pharmacy students) and 15 men (14 medicine and 1 pharmacy student) had already taken the vaccine before the beginning of the research. Among the students who had filled out the first questionnaire and were not previously vaccinated, 34 women (30 medicine and 4 pharmacy students) and 10 male medicine students were eventually vaccinated against HPV. Concerning these two courses evaluated, there was an increase in the rate of vaccination. Between the 140 women that answered the second questionnaire, the rate of vaccination declared prior to the first questionnaire was of $28 \%$, and it increased to $52 \%$ when we included women vaccinated in the three-month gap between questionnaires $(p<0.05)$. For men, the rate was of $16 \%$, and it increased to $27 \%(p>0.05)$.

\section{Discussion}

After having applying the questionnaire to almost 500 Brazilian male and female university students, we observed that there was a greater knowledge related to HPV infection and its consequences among women, especially those in the medicine course. This knowledge was higher among senior students. In all courses and regarding both genders, the majority of the students were able to identify the sexually transmitted nature of the HPV infection, and they were aware that the prevalence of HPV infection peaks between the ages of 15 and 

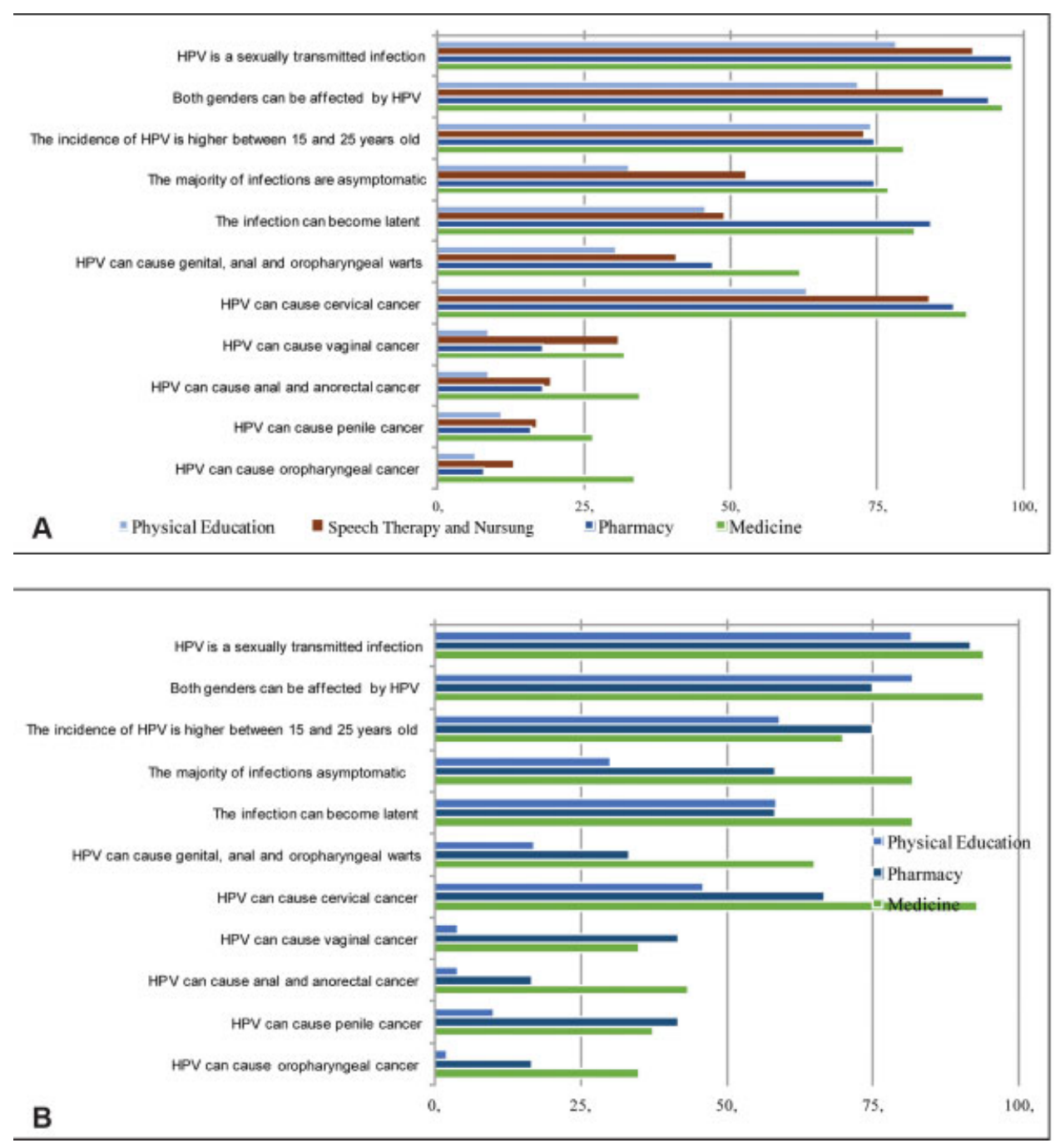

Fig. 1 Knowledge about HPV comparing the percentage of right answers for the female (A) and male (B) students of the courses analyzed.

25 years. Although most students knew about the relationship between HPV infection and cervical cancer, most were unable to identify the association between HPV and other cancers such as vulvar, vaginal, anal, anorectal, penile, and oropharyngeal cancer. Likewise, few students knew about the relationship between genital, anal and oropharyngeal warts and HPV infection. Most students interviewed had not previously been vaccinated against HPV, and, even after being exposed to the correct answers to the questions, the vaccination rate increased only to $52 \%$ for women and $27 \%$ for men within the subsequent three months. It is interesting to report that during this period the vaccine was available at no cost to adults up to 26 years of age by the Brazilian Unified Health System (Sistema Único de Saúde, SUS, in Portuguese).

The importance of HPV education and its vaccine is to enable the public to make a conscious choice about vaccination, knowing the risks of HPV infection and vaccine protection. ${ }^{8}$ Similar to what was shown in our study, Balla et $\mathrm{al}^{9}$ observed that among high-school seniors in Hungary, few had sufficient knowledge regarding HPV infection: although most acknowledged its association with cervical cancer, their knowledge of other diseases was limited.
Those authors also reported better knowledge on the part of female students. For Monteiro et al, ${ }^{10}$ the gender comparison showed a higher vaccination rate among women, which was similar to the findings made by Cooper et $\mathrm{al}^{11}$ that the knowledge and vaccination rate of men in higher education was low: only three quarters had prior knowledge of HPV, and just over half had knowledge about the vaccine. Because cervical cancer is a preventable disease and affects only women, national campaigns have been conducted for years in Brazil and worldwide, focusing on tracking cervical lesions and essentially educating women. Likewise, HPV vaccination was initially targeted at women in Brazil and worldwide, which also favored female education. We also found that $90 \%$ of the women interviewed had already gone to the gynecologist, which can be another cause of the higher knowledge.

In our study, the knowledge regarding almost all aspects related to HPV infection was higher among medical students, regardless of gender, when compared with nursing, speech therapy and pharmacy students, which is in line with the study by Chawla et al, ${ }^{12}$ who found greater knowledge about low-risk HPV and its relation to condylomas when comparing 
Table 4 Attitude toward taking the vaccine and to whom the students would recommend the vaccine comparing gender and class

\begin{tabular}{|c|c|c|c|c|c|c|c|}
\hline Answers & $\begin{array}{l}\text { Freshman women } \\
\mathrm{n}(\%)\end{array}$ & $\begin{array}{l}\text { Senior women } \\
\mathrm{n}(\%)\end{array}$ & p1 & $\begin{array}{l}\text { Freshman men } \\
\mathrm{n}(\%)\end{array}$ & $\begin{array}{l}\text { Senior men } \\
\mathrm{n}(\%)\end{array}$ & $p 2$ & p3 \\
\hline Vaccinated & $44(27)$ & $31(24.4)$ & $p>0.05$ & $10(8.6)$ & $7(8.1)$ & $p<0.05^{*}$ & $p<0.001$ \\
\hline Not vaccinated & 104(63.8) & $89(70.1)$ & & $80(69)$ & 73(84.9) & & \\
\hline Did not know & 15(9.2) & $6(4.7)$ & & 23(19.8) & $2(2.3)$ & & \\
\hline \multicolumn{8}{|c|}{ If not vaccinated (or doesn't know), would get vaccinated after answering this questionnaire } \\
\hline Yes & $78(74.3)$ & $54(61.4)$ & $p<0.05$ & $42(53.9)$ & $46(61.3)$ & $p>0.05$ & $p<0.05$ \\
\hline No & $27(25.7)$ & $34(38.6)$ & & $36(46.2)$ & $29(38.7)$ & & \\
\hline \multicolumn{8}{|c|}{ Would recommend the vaccine } \\
\hline To both genders & $99(60.7)$ & $96(75.6)$ & $p<0.05$ & $76(65.5)$ & $60(69.8)$ & $p>0.05$ & $p>0.05$ \\
\hline Only to women & $58(35.6)$ & $27(21.3)$ & $p<0.05$ & $30(25.9)$ & $19(22.1)$ & $p>0.05$ & $p>0.05$ \\
\hline Only to men & - & - & & $2(1.7)$ & $2(2.3)$ & $p>0.05^{*}$ & $p<0.05^{*}$ \\
\hline
\end{tabular}

Abbreviations: $p 1$, comparing freshman and senior women; $p 2$, comparing freshman and senior men; $p 3$, comparing women and men. Notes: *Analyses compromised due to less than 5 answers had been filled out in the questionnaire. The percentages were calculated based on the number of people that answered the question.

Indian gynecologists with paramedics. Yam et $\mathrm{al}^{13}$ also found greater knowledge among Hong Kong medical students in relation to other courses. In Brazil, Monteiro et al ${ }^{10}$ detected the same gap between literature and medicine students. The lack of knowledge related to HPV is even greater when considering courses not related to health care. In all of the questions in our questionnaire, physical education students performed poorly regardless of gender.

In our study, for both genders, senior students presented better knowledge when compared with freshman students. Similar data have been found in other studies ${ }^{12,14}$ with university students, mainly in health care courses. This may be attributed not only to formal exposure to HPV-related information as part of the curriculum of the courses, but also to cumulative acquisition of HPV-related information from other sources of information, such as lay media. The majority (90\%) of the students were aware of the sexually transmissible nature of HPV. This finding is in line with those from most of the studies performed with young university students globally. ${ }^{6,9,14,15}$ Cervical cancer is unequivocally caused by high-oncogenicrisk HPV infection, and this type of cancer is the third most prevalent neoplasm and the fourth leading cause of cancer death among women. ${ }^{3}$ In our study, $76 \%$ of the participants were aware of the causal nature of HPV in cervical carcinogenesis. This question has been examined by several authors ${ }^{5,9,14-16}$ among students from a variety of courses, with the rate of correct answers ranging from 48 to $98 \%$. Regarding the knowledge that HPV is related to other cancers, the proportion of correct answers did not exceed $40 \%$ for any type of cancer. This knowledge gap was found in other studies $^{9,17}$ for women and men. When we analyzed the relationship between HPV infection and the development of warts in our study and in the literature, knowledge was higher among higher-education students and among women. ${ }^{15,17}$

According to our expectation, only a small proportion of students had been vaccinated against HPV: the rate of students evaluated in the first part of the survey was of $26 \%$ for women and of $8 \%$ for men, being higher among medicine students.
Even within three months of the application of the questionnaire, the vaccination rate increased only to $52 \%$ for women and $27 \%$ for men. In Brazil, the quadrivalent vaccine was approved by the federal regulatory agency (Agência Nacional de Vigilância Sanitária, Anvisa, in Portuguese) in 2006, and it is recommended for adolescents and young adults. In the first years after the approval, the availability of the HPV vaccine was restricted to private clinics, and began to be offered by the SUS in 2014 for girls aged between 11 and 13 years. Since January 2017, its use has been extended to girls aged 9 to 14 years, boys aged 11 to 14 years, and men and women aged between 9 and 26 years who are HIV positive, transplanted or oncological patients on chemotherapy. Data from 2017 showed that vaccination coverage rate among girls aged 9 to 14 years in Brazil was of $82.6 \%$ for the first dose, and of $52.8 \%$ for the second dose. Among boys aged 12 to 13 years, the vaccination rate was of $43.8 \%$ for the first dose. ${ }^{17}$ In addition to not being easily accessible, concerns about the association with sexually transmitted infections (STIs), promiscuity, adverse effects, low recommendation of the vaccine by professionals, costs and lack of knowledge have led to the low rate of HPV vaccination in the target population. ${ }^{13,16}$ Increased awareness had a positive effect on the intention to take the vaccine, and women were more likely to have a positive attitude toward vaccination. ${ }^{9,15}$ Likewise, for Monteiro et al, ${ }^{10}$ more women were interested in taking the vaccine and, in general, higher-education students were more interested in the vaccination. In addition, only a third of the students had interest in taking the vaccine, and those were essentially the ones with the higher knowledge about HPV.

However, in the present study, data from the questionnaire applied three months after the first one showed an insufficient improvement in the proportion of vaccinated students. A study conducted in Scotland by McCusker et $\mathrm{al}^{6}$ evaluated the vaccination rate among medical students in 2008 and 2009. In 2008, no female students had taken all three doses of the HPV vaccine, and, in 2009, after an intense public campaign for HPV vaccination, $58 \%$ of the students had 
taken all three doses. For Attia et al, $^{17}$ the vaccination rate will only grow significantly when the vaccine is administered in programs designed and organized to do so, such as school programs.

The help of governmental and non-governmental organizations working in the health sector is necessary to increase the knowledge on the part of the various health professionals and the general population regarding the various cancers and warts induced by HPV. ${ }^{12}$ Campaigns on the efficacy and safety of the vaccine are also required. The HPV vaccine is already proven to be responsible for the decrease in cases of cervical, oropharyngeal, penile, anal, vulvar and vaginal cancer. Likewise, a significant reduction in genital warts in vaccinated populations is observed. It is extremely important to increase the rate of vaccination among young people, especially before the beginning of sexual activity. ${ }^{18}$

The present study has some limitations. First, due to the fact that some of the courses had already finished the semester, the second questionnaire was only applied to students from two of the five courses that had filled out to the first questionnaire. Second, a homogenization of answers could have occurred by students comparing answers in class. The researchers reinforced the importance of individual answers to minimize this problem. Another limitation is that as the research included only students from health courses, we cannot conclude that the findings of our study represent all university students.

\section{Conclusion}

So far, we conclude that knowledge and vaccination rates against HPV are still low among the university students evaluated in the present study. After we conducted the study, it became clear that higher knowledge is associated with a higher desire to get vaccinated. We hope that the results presented may lead to an investment in PHI programs, first to improve the vaccination rate, and, second, to guide the new university students about the risks of the infection and the methods to prevent it. The moment of starting university seems to be an open window of opportunity for campaigns of awareness once there is a gap in knowledge. It is also an opportunity to improve the rate of vaccination, as almost half of the freshman women declared being sexually inactive and would highly benefit from the vaccination, along with sexually active students who could be vaccinated in an attempt to catch up.

\section{Contributors}

Biselli-Monteiro M developed the study design, planned the analyses, collected the data, performed the literature search, the statistical analyses, prepared the tables and figures, contributed to the interpretation of data, and wrote the manuscript. Ferracini AC collected the data, contributed to the interpretation of data, and writing and revision of the article. Sarian LO performed the statistical analyses, prepared the tables, contributed to the interpretation of data, and to the revision of the article. Derchain SFM contributed to study design, planned the analyses, performed the literature search, contributed to the interpretation of data, and wrote the manuscript. All authors approved the final submitted version.

Conflict of Interests

The authors have no conflict of interests to declare.

\section{Acknowledgments}

The present research was supported by Fundação de Amparo à Pesquisa do Estado de São Paulo (Fapesp, in Portuguese) (under number 2017/03323-6) and by Conselho Nacional de Desenvolvimento Científico e Tecnológico (CNPq, in Portuguese) (under number 303742/2018-6). The research was only possible due to the help of the directors and professors of the courses of pharmacy, speech therapy, nursing, physical education and medicine of Unicamp.

\section{References}

1 de Sanjosé S, Brotons M, Pavón MA. The natural history of human papillomavirus infection. Best Pract Res Clin Obstet Gynaecol. 2018;47:2-13. Doi: 10.1016/j.bpobgyn.2017.08.015

2 Castle PE, Maza M. Prophylactic HPV vaccination: past, present, and future. Epidemiol Infect. 2016;144(3):449-468. Doi: $10.1017 /$ S0950268815002198

3 Forman D, de Martel C, Lacey CJ, Soerjomataram I, Lortet-Tieulent J, Bruni L, et al. Global burden of human papillomavirus and related diseases. Vaccine. 2012;30(Suppl 5):F12-F23. Doi: 10.1016/j.vaccine.2012.07.055

4 Bruni L, Diaz M, Barrionuevo-Rosas L, Herrero R, Bray F, Bosch FX, et al. Global estimates of human papillomavirus vaccination coverage by region and income level: a pooled analysis. Lancet Glob Health. 2016;4(7):e453-e463. Doi: 10.1016/S2214-109X (16)30099-7

5 Nagpal J, Linares LO, Weiss J, Schlecht NF, Shankar V, BraunCourville D, et al. Knowledge about human papillomavirus and time to complete vaccination among vulnerable female youth. J Pediatr. 2016;171:122-127. Doi: 10.1016/j.jpeds.2015.12.070

6 McCusker SM, Macqueen I, Lough G, Macdonald AI, Campbell C, Graham SV. Gaps in detailed knowledge of human papillomavirus (HPV) and the HPV vaccine among medical students in Scotland. BMC Public Health. 2013;13:264. Doi: 10.1186/1471-2458-13-264

7 R Core Team. R: a language and environment for statistical computing [Internet]. Vienna: R Foundation for Statistical Computing; 2018 [cited 2018 Aug 10]. Available from: https://www.Rproject.org/

8 Ragin CC, Edwards RP, Jones J, Thurman NE, Hagan KL, Jones EA, et al. Knowledge about human papillomavirus and the HPV vaccine-a survey of the general population. Infect Agent Cancer. 2009;4(Suppl 1):S10. Doi: 10.1186/1750-9378-4-S1-S10

9 Balla BC, Terebessy A, Tóth E, Balázs P. Young Hungarian students' knowledge about HPV and their attitude toward HPV vaccination. Vaccines (Basel). 2016;5(1):1-9. Doi: 10.3390/vaccines5010001

10 Monteiro DLM, Brollo LCS, Souza TP, Santos JRPD, Santos GR, Correa T, et al. Knowledge on the HPV vaccine among university students. Rev Inst Med Trop São Paulo. 2018;60:e46. Doi: 10.1590/s1678-9946201860046

11 Cooper DL, Zellner-Lawrence T, Mubasher M, Banerjee A, Hernandez ND. Examining HPV awareness, sexual behavior, and intent to receive the HPV vaccine among racial/ethnic male college students 18-27 years. Am J Men Health. 2018;12(6): 1966-1975. Doi: 10.1177/1557988318803163

12 Chawla PC, Chawla AK, Shrivastava R, Shrivastava A, Chaudhary S. Situation analysis of existing facilities for screening, treatment and prevention of cervical cancer in hospitals/primary health 
centers of Delhi-NCR region, India. Asian Pac J Cancer Prev. 2014; 15(13):5475-5482. Doi: 10.7314/apjcp.2014.15.13.5475

13 Yam PWA, Lam PL, Chan TK, Chau KW, Hsu ML, Lim YM, et al. A cross sectional study on knowledge, attitude and practice related to human papillomavirus vaccination for cervical cancer prevention between medical and non-medical students in Hong Kong. Asian Pac J Cancer Prev. 2017;18(6):1689-1695. Doi: 10.22034/ APJCP.2017.18.6.1689

14 Jelastopulu E, Fafliora E, Plota A, Babalis V, Bartsokas C, Poulas K, et al. Knowledge, behaviours and attitudes regarding HPV infection and its prevention in female students in West Greece. Eur Rev Med Pharmacol Sci. 2016;20(12):2622-2629

15 Chiang VC, Wong HT, Yeung PC, Choi YK, Fok MS, Mak OI, et al. Attitude, acceptability and knowledge of hpv vaccination among local university students in Hong Kong. Int J Environ Res Public Health. 2016;13(5):486. Doi: 10.3390/ijerph13050486
16 Sherman SM, Bartholomew K, Denison HJ, Patel H, Moss EL, Douwes J, et al. Knowledge, attitudes and awareness of the human papillomavirus among health professionals in New Zealand. PLoS One. 2018;13(12):e0197648. Doi: 10.1371/journal.pone.0197648

17 Attia AC, Wolf J, Núñez AE. On surmounting the barriers to HPV vaccination: we can do better. Ann Med. 2018;50(3):209-225. Doi: 10.1080/07853890.2018.1426875

18 Ministério da Saúde. Secretaria de Vigilância em Saúde. Departamento de Vigilância das Doenças Transmissíveis. CoordenaçãoGeral do Programa Nacional de Imunizações [Internet]. Informe técnico da ampliação da oferta das vacinas papiloma vírus humano 6,11,16 e 18 (recombinante) - vacina HPV quadrivalente e meningocócica C (conjugada). Brasília, DF: Ministério da Saúde; 2018 [cited 2018 Dec 02]. Available from: http://portalarquivos2. saude.gov.br/images/pdf/2018/marco/14/Informe-T-cnico-HPVMENINGITE.pdf 